\title{
Learning from Complementary Ways of Developing Experimental Competences
}

\section{Aprendizaje a partir de maneras complementarias de desarrollar capacidades experimentales}

\author{
Natércia Maria Lima , Maria Clara Viegas ², Francisco José García-Peñalvo ${ }^{3}$

\begin{abstract}
School of Engineering (ISEP), Polytechnic of Porto, Portugal. nmm@isep.ipp.pt
Research Centre in Industrial Technology and Engineering (CIETI), School of Engineering (ISEP), Polytechnic of Porto, Portugal. mom@isep.ipp.pt

${ }^{3}$ Research Institute for Educational Sciences (IUCE), Faculty of Sciences, GRIAL Research Group, University of Salamanca, Spain. fgarcia@usal.es
\end{abstract}

\begin{abstract}
Engineering education has solid needs of experimental competences development. Nowadays these competences can be worked not only in traditional laboratories (hands on) but also through the use of computer simulations and remote labs. The use of diversified methods in education and the exploration of new resources and techniques in classroom may allow teachers to motivate more students, and capture their attention due to their different learning styles.
\end{abstract}

The main objective of this project is to better understand the effects on students' learning outcomes in different contexts (country, type of institution, background, etc.). Students are subjected to similar design approaches that all use an enquiry-based teaching and learning methodology. The methodology of the didactical implementation is based on the simultaneous use of experimental resources (hands on, simulation and remote labs) together with calculus, in class and assessment. To accomplish this research, several insights must be taken into consideration, including the teachers' mediation in class, in each case, and the didactical implementations adaptations, but also external factors, such as socio-cultural and/ or political factors.

\section{Keywords}

Remote Laboratory; VISIR; Learning Outcomes; Engineering Education

\section{Resumen}

La educación en ingeniería tiene sólidas necesidades de desarrollo de competencias experimentales. Hoy en día estas competencias pueden desarrollarse no solo en los laboratorios tradicionales (hands-on), sino también a través de simulaciones y laboratorios remotos. El uso de métodos diversificados en la educación y la exploración de nuevos recursos y técnicas en el aula puede permitir que los maestros motiven a más estudiantes y capten su atención.

El objetivo principal de este diseño es comprender mejor los efectos sobre los resultados de aprendizaje de los estudiantes en diferentes contextos (país, tipo de institución, etc.), cuando están sujetos a enfoques de diseño similares utilizando una metodología de enseñanza y aprendizaje basada en la investigación. Esta metodología emplea el uso simultáneo de recursos experimentales (handson, simulaciones y laboratorios remotos) junto con cálculo, en clase y en evaluación. Para lograr este objetivo, hay que tener en cuenta varios puntos de vista, como la mediación de los profesores en cada caso y las adaptaciones didácticas, además de factores externos, como por ejemplo los factores socioculturales y/o políticos.

\section{Palabras Clave}

Laboratorios Remotos; VISIR; Resultados de Aprendizaje; Educación en Ingeniería 


\section{Context and motivation that drives the dissertation research}

Engineering education, regardless thearea, has solid needs of experimental competence developments (Feisel \& Rosa, 2005; Jara, Candelas, Puentes, \& Torres, 2011; Gustavsson, et al., 2011), as engineering is a practical profession where doing is the key. These competences were traditionally developed in laboratories, along their education. In the last decades, there was a general growth of the number of students attending higher education and as a consequence the physical resources available were no longer sufficient. Simultaneously, with Bologna Process, laboratory time was reduced in most European Engineering Schools and the number of students per class increased, due to economic restrictions (Crosier \& Parvera, 2013).

About the same time, scientists start developing computer simulations and remote laboratories, allowing students to practice some experimental skills in a different manner - giving them freedom to organize their own learning activities, according to the perception of their learning needs and extended access to the learning resources (access many times and from different places), reinforcing students' autonomy (Gustavsson, et al., 2011).

Nowadays and even though there is still some controversy about these new technologies efficacy (Corter, et al., 2007; Corter, Esche, Chassapis, Ma, \& Nickeson, 2011), teachers are often using these resources either instead or as a complement to the traditional hands-on lab. As a matter of fact, remote labs emerge as one of the main instructional technologies adopted and valued in engineering education, corresponding to one of the major shifts in engineering education in the last 100 years (Froyd, Wankat, \& Smith, 2012).

The use of these computer based resources poses new questions regarding pedagogical and didactical issues, as its' use, on their own, may even be prejudicial - some of these tools are quite complex and not immediately understandable to students, leading them to frustration and dropping out the task (Sticker, Lookabaugh, Santos, \& Barnes, 2005). Students also need to understand the major differences in the type of measurements that can be obtained from these different resources: model results from simulations and real experimental results from hands-on and remote labs. In this sense, remote labs give the advantages of simulations and the advantages of working with real things. Still remote labs are not the perfect solution - the underlying technology of the laboratory (as the interface of the equipment) may influence learning effectiveness (Corter, et al., 2007; Corter, Esche, Chassapis, Ma, \& Nickeson, 2011; Marques, et al., 2014) and some authors even regard it as inhibitors of students' learning (Ma \& Nickerson, 2006). On the other hand, some studies present evidence that the use of these technology-enabled lab formats (simulation and remote labs) can improve students' 
learning outcomes, as long as teachers realize that the educational objectives associated with each of them may be different (Ma \& Nickerson, 2006; Brinson, 2015). Each method (the use of simulation, remote lab and hands on) allows the developing of different competences, so teachers should be aware of this fact when deciding which method or combination of methods to use. Although there are already, in literature, some experiences describing the simultaneous use of these resources, these experiences are small-scaled, particularly for remote labs, and no significant and consistent difference between hands-on, simulation and remote labs stand out (Ma \& Nickerson, 2006; Viegas, Lima, Alves, \& Gustavsson, 2014; Lima, Alves, Viegas, \& Gustavsson, 2015; Alves, Viegas, Lima, \& Gustavsson, 2016); (Alves, Lima, Alves, \& García-Peñalvo, 2017). Nevertheless, it is well studied in literature that teachers can reach more students, if they diversify the methods and techniques used in classroom, including the use of simulations and remote labs. Most believe that this is mainly due to students' different learning styles (Felder \& Silverman, 1988; Richardson, 2011). Still, more recently, some authors believe that learning styles are an urban legend in education and one should focus on the fundamental things that learners have in common (not denying the individual differences) (Kirschner \& Merriënboer, 2013).

It should also be taken into account the role of the teacher in the classroom. It is well established in literature the importance of teachers' mediation role - there are some characteristics that can lead students' to productive engagement in the tasks (Cunha, Saraiva, Santos, Dinis, \& Lopes, 2014; Sarabando, Cravino, \& Soares, 2016).

A remote lab is a laboratory in which the user and the physical apparatus are physically apart. To perform the experiment, the user has to access the Internet and usually a particular user interface to operate the remote equipment, being able to configure and control the physical parameters of a real experiment (Alves, et al., 2011).

One of the most used remote laboratories in Engineering Education is VISIR (Virtual Instrument Systems in Reality). VISIR initially started in 1999, at the Blekinge Institute of Technology (BTH) in Sweden (Figures 1 and 2) and is a combination of open source software packages and commercial equipment from National Instruments (NI) (Claesson \& Hakansson, 2012). It deals with experiments with electrical and electronics circuits and was considered in 2015 the best remote lab in the world by the Executive Committee of the Global Online Laboratory Consortium ([IAOE] Winners of the GOLC Online Laboratory Award, 2015). It replicates a physical breadboard, showing all available components and the instrument front panels (on the PC screen), which enables the user to connect the desired circuit and analyze its behavior with several instruments. (Gustavsson, et al., 2011; Tawfik, et al., 2011). BTH research group is still responsible for maintaining and updating the VISIR distribution that is available as open source. Nowadays VISIR is installed in eight different Higher Education Institutions $(\mathrm{HEI})$, in six different countries (Sweden, Austria, Portugal, Spain, Georgia and India). 


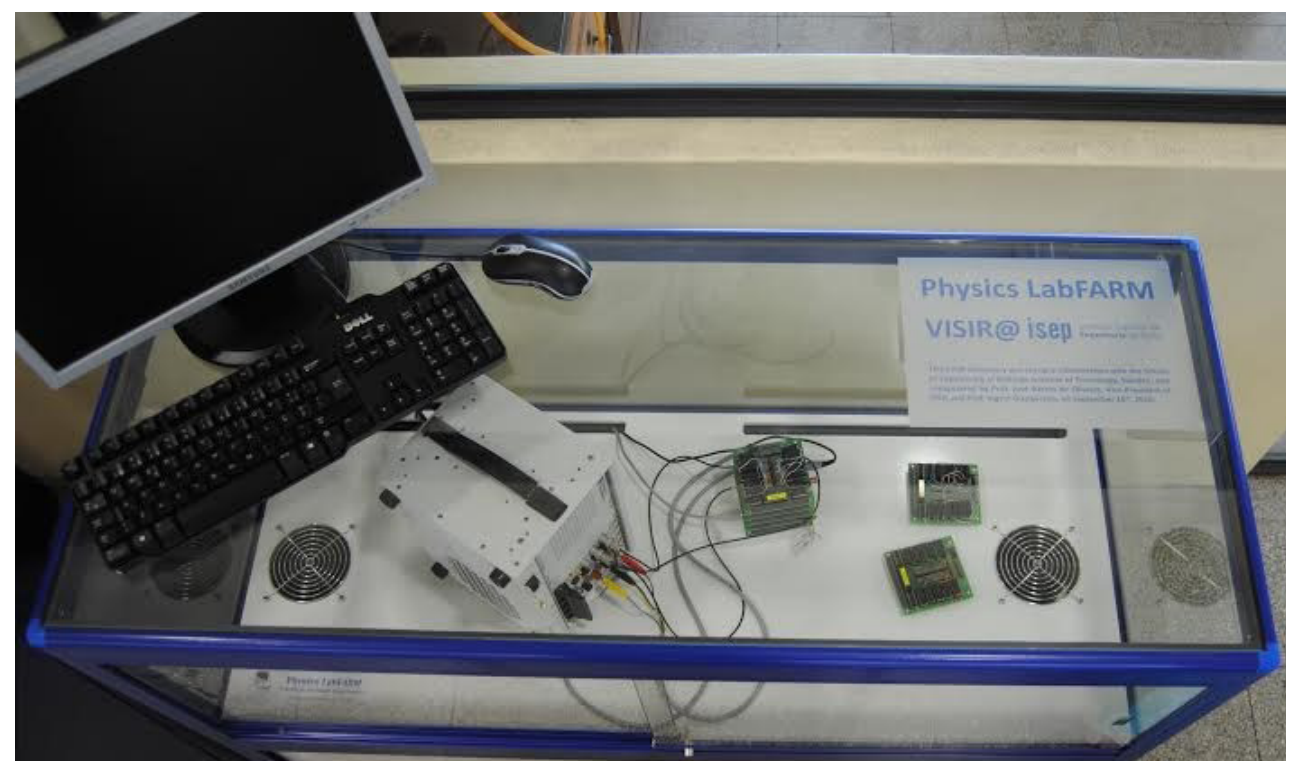

Figure 1. VISIR System at ISEP (Polytechnic of Porto, Portugal).

The European Countries VISIR users have, along the time, set cooperative and institutional ties and thought of creating a consortium/project to replicate in South America (Brazil and Argentina) the level of cooperation and novelty associated with VISIR in Europe. This lead to the VISIR+ Project, started in November 2015, being Polytechnic of Porto, School of Engineering/CIETI-LABORIS the project coordinator. Through this project, a VISIR system is being installed in each Latin American (LA) partner (in five $\mathrm{HEI}$ ) and it will be used not only by the owner institution (the one, in which, VISIR is installed) but also for other secondary/professional/higher education institutions, under the initial guidance of an European partner. The fact each LA HEI possess a VISIR system is expected to contribute to an increased sense of ownership, both by students and teachers, promoting its adoption.

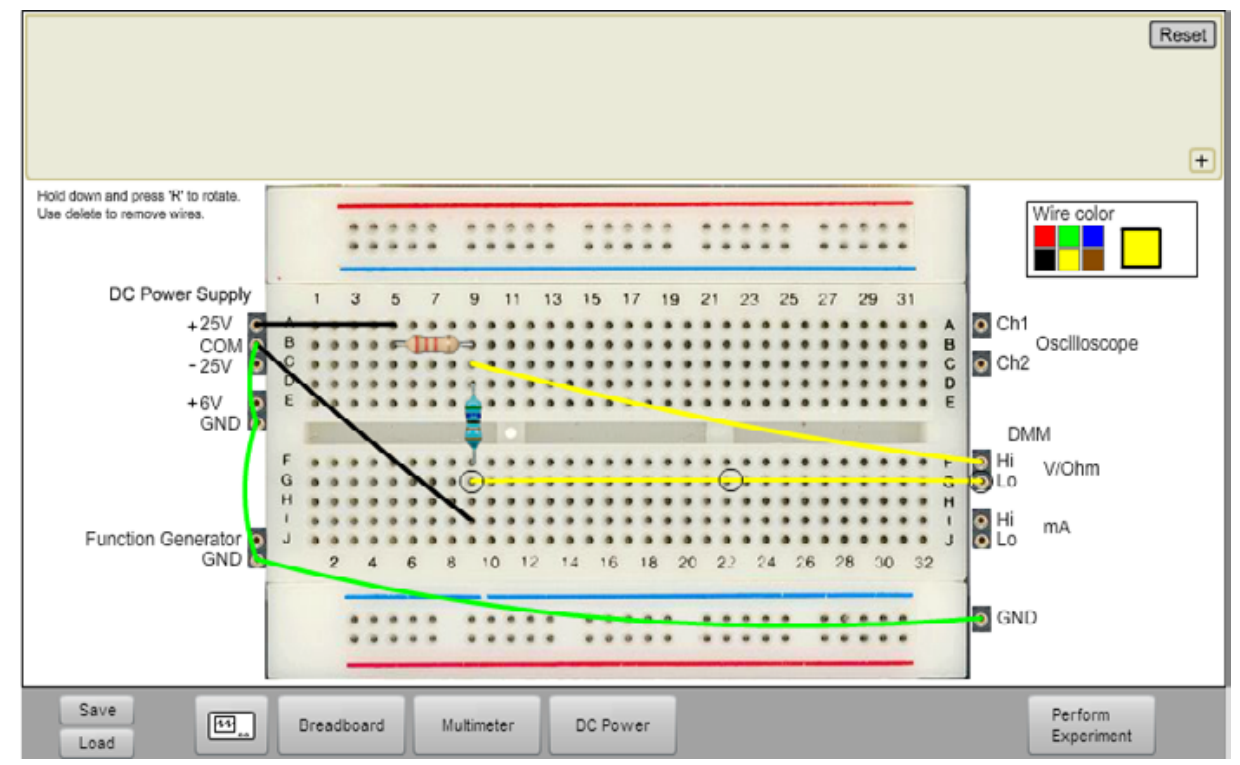

Figure 2. Performing an experiment using VISIR.

By now, thousands of students have already used VISIR, with learning gains (Tawfik, et al., 2011; Alves, et al., 2011), but in most cases, this resource was not used simultaneously with other resources, such 
as, simulation and hands-on lab, or calculus, except for one small scale didactical experiment (Viegas, Lima, Alves, \& Gustavsson, 2014; Lima, Alves, Viegas, \& Gustavsson, 2015; Alves, Viegas, Lima, \& Gustavsson, 2016). In this case, it was used an enquiry based teaching and learning methodology and the course curriculum as well as the didactical implementation design indication were described.

VISIR + Project also aims to define and develop a set of educational modules comprising hands-on, virtual and VISIR remote lab, together with calculus, following an enquiry-based teaching and learning methodology. This will allow to conduct a research study to better understand the effects of these simultaneous resources usage in terms of students learning and satisfaction.

\section{Hypothesis/Thesis and/or problem statement}

The underlying problematic that can be tackled in this thesis project is to better understand how and which students' learning outcomes are affected by the use of different experimental resources (hands-on, simulated and remote labs) together with calculus, in class and assessment, applying an enquiry-based teaching and learning didactic methodology.

The research study will be conducted in several different contexts, allowing to explore factors that somehow may affect students' engagement, motivation and learning outcomes.

Considering electric circuit analysis, we have to distinguish between CC (continuum current) and AC (alternate current)-AC circuit analysis and calculus imply using vector and complex numbers notations, being quite more challenging than DC analysis. So, several insights must be taken into consideration, including also external factors, such as teacher mediation or other contextual influences.

\section{Research objectives/goals}

Considering the problematic described in the previous section, the main goal of this work aims to study 3 Research Questions (RQ):

- RQ1: In which way the use of simultaneous resources, applying an enquiry-based teaching and learning methodology, contributes to promote students' autonomous continuum work and engagement?

- RQ2: Is the level of competence under development affect students engagement with using the different resources?

- RQ3: Are there teacher mediation traces (while using simultaneous resources) that can be linked to better student performances? 


\section{Research approach and methods, including relevant rationale}

This research will use a mixed methods approach, that is, it will be incorporated in a unique research study methods of colleting or analyzing data from the quantitative and qualitative approaches (Creswell, 2014).

A case study methodology will be used, a specific instance that is frequently used to illustrate a more general principle, as Cohen defines it (Cohen, Manion, \& Morrison, 2007). They are descriptive and detailed with a narrow focus, combining objective and subjective data, establishing cause and effect - observing effects in real context, recognizing that contexts are a powerful determinant for both causes and effects (Cohen, Manion, \& Morrison, 2007). Its purpose is to solve a particular problem and to produce guidelines to improve practice, enabling readers to understand how ideas and abstract principles can fit together, opting for analytical rather than statistical generalization. Generally speaking, intervention studies are considered more powerful than case studies, but under the circumstances, case studies are the best approach.

A key issue in this research method is the selection of information: it should be collected/recorded not only typical, representative occurrence but also unrepresentative or even critical incidents, as they can be crucial to the understanding of the case (Cohen, Manion, \& Morrison, 2007). There is a diverse range of techniques employed in the collection and analysis of both quantitative and qualitative data, depending upon the question that the researcher wants to answer. Nevertheless, the researcher should spend time on-site interacting with the people studied and the data collection must be extensive and drawn from multiple sources such as direct or participant observations, interviews, archival records or documents, physical artefacts and audio-visual materials (Williams, 2007).

The cases that will be used are teachers/students from the target courses where the didactical implementations will take place. These courses deal with electric and electronic circuits and are from five LA HEl:

- Federal Institute of Education, Science and Technology of Santa Catarina, Brazil (IFSC) public vocational and technological education institution, with approximately 24000 students;

- Federal University of Santa Catarina, Brazil (UFSC): public university with 1651 professors, 2874 technical and administrative staff, more than 1800 lines of research and 34000 students:

- Pontifical Catholic University of Rio de Janeiro, Brazil (PUC): private University, with 15000 students; 
- School of Exact Sciences and Technologies - National University of Santiago del Estero, Argentina (UNSE): public university, with 7 engineering programs and 12000 thousands students.

- National University of Rosario, Argentina (UNR): public institution offering 124 postgraduate courses, 63 college degrees, 15 technical degrees and 53 intermediate level colleges degrees.

The data collection to tackle each RQ, is summarized in table 1 (most of these data will be collected in VISIR+ Project, even though not to address the same purposes).

\begin{tabular}{|c|c|c|c|c|}
\hline & Collected Data & RQ1 & $\mathrm{RQ2}$ & RQ3 \\
\hline \multirow{7}{*}{ 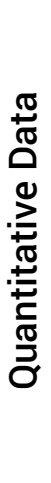 } & VISIR Labs access logs' (quantity and distribution over time) & $\checkmark$ & $\checkmark$ & \\
\hline & Simulated Labs access logs' (quantity and distribution over time) & $\checkmark$ & $\checkmark$ & \\
\hline & Presences to classes & $\checkmark$ & & \\
\hline & LMS $\left(^{*}\right)$ course page - number of accesses and distribution over time & $\checkmark$ & & \\
\hline & Students final grades & $\checkmark$ & $\checkmark$ & $\checkmark$ \\
\hline & Students grades per component/task & $\checkmark$ & $\checkmark$ & $\checkmark$ \\
\hline & Students grades per AC/DC & & $\checkmark$ & \\
\hline \multirow{7}{*}{ 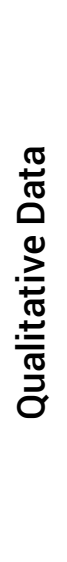 } & Participation and/or delivery of proposed tasks (in due time) & $\checkmark$ & & \\
\hline & LMS course page - contents accessed, participation in forums & $\checkmark$ & & \\
\hline & $\begin{array}{l}\text { Course Curricula: contents, education materials, T\&L strategies, assessment } \\
\text { tools }\end{array}$ & $\checkmark$ & $\checkmark$ & $\checkmark$ \\
\hline & Students' PLEQ $(* \star)$ questionnaire & $\checkmark$ & $\checkmark$ & $\checkmark$ \\
\hline & Teachers interview and/or informal comments & $\checkmark$ & $\checkmark$ & $\checkmark$ \\
\hline & Types of assessment tools and its' distribution along the semester & & & $\checkmark$ \\
\hline & $\begin{array}{c}\text { Time used in giving feedback and type of feedback given to each assessment } \\
\text { task }\end{array}$ & & & $\checkmark$ \\
\hline
\end{tabular}

(*) Learning Management System

(**) Perception and Learning Environment Questionnaire

Table 1. Data collection to answer RQs.

\section{Results to date and their validity}

To evaluate VISIR implementation and usage done so far, a systematic literature review has been conducted in order to better understand the state of theart regarding VISIR's didactical implementations impact (Lima, Viegas, \& Garcia-Peñalvo, 2016).

The results of this review contributed to the evaluation of the remote lab VISIR in terms of didactical implementations, including educational goals, learning achievements and competences. And to a less extent to some technical aspects that could be improved in VISIR itself and consequently improve its interaction with students. 
In this literature review, there were identified and analyzed 22 cases, each case representing a different course where VISIR was implemented, covering more than 4400 students, from different educational levels. From this analysis it was clear that VISIR system is a functional and useful learning instrument, well accepted by students, which should be used as a complement to hands-on lab or as a tool for distance learning.

From the study, it is also evident VISIR improves students' competences, knowledge, and students' confidence in lab, their enthusiasm and motivation. Nonetheless it's very difficult to isolate VISIR's contribution to these results from the other resources used in each case.

Although it is important to set up the VISIR tasks according to the leaning goals and students' knowledge, there were identified some factors that somehow, compromise student's engagement and motivation. These were: the VISIR contribution to the final grade, teachers' continuous attention to VISIR throughout the course and teachers' supervision in students first time with VISIR.

Just in one small scale case was reported the course curriculum and the didactical implementation design indication. In this case, the designed based on the learning outcomes teachers want students to develop and the tasks used to it were clearly specified. VISIR was used with other resources (simulation, hands on and calculus) following an enquiry based methodology and it seems that this methodology enhanced students learning and the development of high order skills. This kind of work tends to be more helpful to other teachers who want to use VISIR. In this way, they can understand more accurately how VISIR may be incorporated in the curriculum and what kind of teacher' mediation they should use. The obtained results may also be more clearly read.

\section{Dissertation status}

Due to the conducted literature review, the relevant facts considering VISIR usage and implementation were identified.

Considering data collection, the first didactical implementation - at least, one course per LA HEI - took place in the second semester of the academic year 2016 (August - December). In both semesters of 2017 academic year, starting in February 2017, it will be implemented in several courses per institution and more data will be gathered.

The first set of data will be treated from February 2017. It will be done a qualitative and quantitative cross analysis, considering several items, namely: Brazilian students/Argentine students, Public Institutions/Private Institutions, Polytechnic /University; Large Institutions/Small Institutions. 
Within the framework of VISIR+ Project it was, recently, published a work focusing in spreading the usage of remote labs (Alves, et al., 2016) and a further publication will be presented shortly:

- $14^{\text {th }}$ International Conference on Remote Engineering and Virtual Instrumentation (REV2017), USA, 15-17 March 2017 - "Spreading the use of remote lab VISIR over Latin America (VISIR+ Project Preliminary results of the training actions)", accepted for publication.

\section{Current and expected contributions}

This work is expected to further nurture the research work around VISIR, spreading its usage and dissemination.

In fact, in order to overcome some of the limitations of the actual VISIR system and to make the most of it, the BTH founders proposed to create a federation of VISIR laboratories that could be accessed by any partner and would include a free-access repository for sharing learning resources.

\section{Acknowledgements}

The authors would like to acknowledge the support of the VISIR Community as well as the financial support provided by the Foundation for Science and Technology Project, FCT UID/EQU/00305/2013.

This research work is made within the University of Salamanca PhD Program on Education in the Knowledge Society.

\section{References}

[IAOE] Winners of the GOLC Online Laboratory Award. (2015, February 11). Retrieved 2016, from http:// lists.online-lists.org/pipermail/iaoe-members/2015-February/000120.html

Alves, G., Fidalgo, A., Marques, M. A., Viegas, C., Felgueiras, M., Costa, R., . . Kulesza, W. (2016). Spreading remote labs usage: A System - A Community - A Federation. Proceedings of the 2nd International Conference of the Portuguese Society for Engineering Education (CISPEE2016). Vila Real, Portugal. doi:10.1109/cispee.2016.7777722

Alves, J., Lima, N., Alves, G., \& García-Peñalvo, F. J. (2017). Adjusting Higher Education Competences to Companies Professional Needs: A Case Study in an Engineering Master's Degree. International Journal of Human Capital and Information Technology Professionals (IJHCITP), 8(1), 66-78. doi:10.4018/ IJHCITP.2017010105 
Alves, G., Marques, M., Viegas, C., Costa Lobo, M. C., Barral, R., Couto, R., ... Gustavsson, I. (2011). Using VISIR in a large undergraduate course: Premiminary assessments results. Global Engineering Education Conference (EDUCON). doi:10.1109/EDUCON.2011.5773288

Alves, G., Viegas, C., Lima, N., \& Gustavsson, I. (2016). Simultaneous Usage of Methods for the Development of Experimental Competences. International Journal of Human Capital and Information Technology Professionals, 7(1), 48-63. doi:10.4018/IJHCITP.2016010104

Brinson, J. R. (2015). Learning outcome achievment in non-traditional (virtual and remote) versus traditional (hands-on) laboratories: A review of the empirical reserach. Computers \& Education, 87, 218-237. doi:10.1016/j.compedu.2015.07.003

Claesson, L., \& Hakansson, L. (2012). Using an Online Remote Laboratory for Electrical Experiments in Upper Secondary Education. International Journal of Online Engineering (iJOE), 8(S2). doi:10.3991/ ijoe.v8iS2.1941

Cohen, L., Manion, L., \& Morrison, K. (2007). Research Methods in Education, 6th Edition. London and New York: Routledge, Taylor \& Francis Group.

Corter, J. E., Nickerson, J. V., Esche, S., Chassapis, C., Im, S., \& Ma, J. (2007). Constructing reality: A study of remote, hand-on and simulated laboratories. ACM Transactions on Computer Human Interaction, 14(2). doi: 10.1145/1275511.1275513

Corter, J., Esche, S., Chassapis, C., Ma, J., \& Nickeson, J. (2011). Process and learning outcomes from remotely-operated, simulated and hands-on student laboratories. Computers \& Education, 57, 20542067. doi:10.1016/j.compedu.2011.04.009

Creswell, J. W. (2014). Research Design: Qualitative, Quantitative and Mixed Methods Approaches, 4th Edition. Thousand Oaks, CA, USA: SAGE.

Crosier, D., \& Parvera, T. (2013). The Bologna Process: Its impact on higher education development in Europe and beyond. Paris: United Nations Educational, Scientic and Cultural Organization.

Cunha, A. E., Saraiva, E., Santos, C. A., Dinis, F., \& Lopes, J. B. (2014). Teacher mediation actions and students' productive engagement during the use of computer simulations in physical science classrooms. Procedia Technology 13(2014), 76-85. doi:10.1016/j.protcy.2014.02.011

Feisel, L. D., \& Rosa, A. J. (2005). The Role of the Laboratory in Undergraduate Engineering Education. Journal of Engineering Education, 94(1), 121-130. doi:10.1002/j.2168-9830.2005.tb00833.x 
Felder, R., \& Silverman, L. (1988). Learning and Teaching Styles in Engineering Education. Engineering Education, 78(7), 674-681.

Froyd, J. E., Wankat, P. C., \& Smith, K. A. (2012). Five Major Shifts in 100 Years of Engineering Education. Proceedings of the IEEE, 100, 1344-1360. doi:10.1109/JPROC.2012.2190167

Gustavsson, I., Alves, G., R., C., Nilsson, K., Zackrisson, J., Hernandez-Jayo, U., \& Garcia_Zubia, J. (2011). The VISIR Open Lab Platform 5.0 - an architecture for a federation of remote laboratories. REV 2017: 8th International Conference on Remote Engineering and Virtual Instrumentation. Brasov, Romania.

Jara, C., Candelas, F., Puentes, S., \& Torres, F. (2011). Hands-on experiences of undergraduate students in Automatics and Robotics. Computer and Education, 57, 2451-2461. doi:10.1016/j. compedu.2011.07.003

Kirschner, P. A., \& Merriënboer, J. J. (2013, June 14). Do Learners Really Know Best? Urban Legends in Education. Educational Psychologist, 48(3), 169-183. doi:10.1080/00461520.2013.804395

Lima, N., Alves, G., Viegas, C., \& Gustavsson, I. (2015). Combined Efforts to develop students experimental competences. Proceedings Exp.at'75 3rd International Experimental Conference. New York, USA: ACM. doi: 10.1109/expat.2015.7463273

Lima, N., Viegas, C., Alves, G., \& García-Peñalvo, F. J. (2016). VISIR's Usage as an Educational Resource: a Review of the Empirical Research. In F. J. García-Peñalvo (Ed.), Proceedings of the Fourth International Conference on Technological Ecosystems for Enhancing Multiculturality (TEEM'16) (Salamanca, Spain, November 2-4, 2016) (pp. 893-901). New York, NY, USA: ACM. doi:10.1145/3012430.3012623

Ma, J., \& Nickerson, J. (2006). Hands-on, Simulated and Remote Laboratories: A Comparative Literature Review. ACM Computer Surveys, 38(3). doi: 10.1145/1132960.1132961

Marques, A., Viegas, C., Costa-Lobo, C., Fidalgo, A., Alves, G., Rocha, J., \& Gustavsson, I. (2014). How Remote Labs Impact on Course Outcomes: Various Practises Using VISIR. IEEE-Transactions on Education, 57(3), 151-159. doi:10.1109/TE.2013.2284156

Richardson, J. (2011). Approaches to studying, conceptions of learning and learning styles in higher education. Learning and Individual Differences, 21, 288-293. doi:10.1016/j.lindif.2010.11.015

Sarabando, C., Cravino, J. P., \& Soares, A. A. (2016). Improving student understanding of the concepts of weight and mass with a computer simulation. Journal of Baltic Science Education, 15(1), 109-126.

Sticker, D., Lookabaugh, T., Santos, J., \& Barnes, F. (2005). Assessing the effectiveness of remote networking laboratories. 35th ASEE/IEEE Frontiers in Education Conference. Indianapolis: IN. 
Tawfik, M., Sancristobal, E., Martin, S., Gil, C., Pesquera, A., Losada, P., . . Alves, G. (2011). VISIR deployment in undergraduate engineering practises. Frontiers in Education Conference.

Viegas, C., Lima, N., Alves, G., \& Gustavsson, I. (2014). Improving students experimental competences using simultaneous methods in class and assessments. TEEEM'14 Proceedings of the second International Conference on Technological Ecosystems for Enhancing Multiculturality (pp. 125-132). Salamanca, Spain: ACM New York. doi: 10.1145/2669711.2669890

Williams, C. (2007). Research Methods. Journal of Business \& Economic Research, 5(3). doi:10.19030/ jber.v5i3.2532 